\title{
EDITORIAL
}

\section{What's Queer and New in Apocalyptic Times}

Queer of color critique offers a different perspective on mess. It proposes not so much a way out, but rather a survival guide in wading through the neoliberal mess. (Manalansan 2018, I288)

What was the open question Muñoz left us with? It was this: What if the "queer" in queer theory were temporarily bracketed in order to examine everything that gathered under its sign and everything that remained beyond its purview? (Halberstam and Nyong'o 20I8, 453)

THIS ISSUE OF lambda nordica began from a familiar framing in these times: What is "new" in queer studies? As editors, we eagerly awaited submissions in the form of surprising, interesting, bold, and new research from queer scholars. The present issue, as long and late in it's making as the Swedish government, is the outcome and it presents a number of emerging scholars and topics that are being pursued in $\mathrm{PhD}$ theses and postdoctoral projects in a range of disciplines, as well as reflections on new queer art. In this editorial, we want to briefly reflect on the past year and on what we, with José Esteban Muñoz' words above, might call the "mess we are in" tells us about queer studies and the politics of newness. Do we need to bracket queer in order to let queer do new work? 
One new theme in queer studies is of course the increasingly heightened debate and anxiety around open access and the ranking of journals. While nobody seems to know what the future of journal publishing will be when the big commercial publishers can no longer rely on selling our work to readers, everyone seems anxious about pressures to be productive and useful. Scholars are increasingly encouraged to publish early and article writing is a skill that most are expected to master quite early in a scholarly career. While this is an important skill, journal editors often talk about how the pressure to publish has led to a substantial increase in submissions and a tendency to submit premature and underdeveloped ideas.

Curiously, in the past year, lambda nordica has had a noticeable decline in submissions to the journal. We have pondered possible explanations for this shift. Of course, as a small journal, struggling to some extent with the new political economy of publishing and the importance of ranking, inclusion in databases and citations, not to mention the need for social media presence, we know we are up against giants, and as they say on airlines, we do realize that our authors have a range of choices. Sometimes prospective authors tell us that their institutions do not allow publication in anything but high-ranking journal, or that institutions are rewarded according to such a system. As a queer journal that has been at the forefront of the positive dimensions of open access, namely the democratization of knowledge, we continue to imagine a future of the journal where we provide a space for emerging and established authors both to present new directions and to stay with the trouble of all that remains unsolved.

Another question is the state of funded research on queer related topics. Scrolling through the fall's announcements from Nordic research funders, one notices a handful of projects on queer topics. One is our editorial board member Jens Rydström's new project, “A Nordic Queer Revolution: Formations of Homophile, Queer, and Trans Activism in Denmark, Norway, and Sweden, I948-2017," involving several other researchers from Norway and Sweden, which aims to take stock of the shifting nature of queer movements in the Nordic region. Another im- 
portant Nordic project is editorial board member Elisabeth Engebretsen's NOP-HS workshop Transforming Identities, which is taking stock of the phenomenon known as identity politics. We look forward to learning from these and other projects and from the growing number of $\mathrm{PhD}$ theses that explore new subjects. Scholars who have been long in the field might find the possibility of exploring queer themes in one's thesis, itself a relatively new phenomenon. An upcoming regional event for queer scholars in the Stockholm area has attracted over thirty interested researchers, which indicates the continued need for scholarly gatherings and collaborations. In this issue, articles by several emerging scholars point to the continued interest in everyday politics of language and kin-making, as well as of finding ways to navigate new forms of gender in digital worlds, domestic practices, and pre-schools.

\section{The Queer Politics of Newness}

Shifting our approach to the theme of this issue, let us briefly consider what it means to ask about what is new in times deeply formed by political resistance to ideas of renewal and recycling. Clearly, the very imperative toward newness, like the pressures to publish, is indicative of the accelerated speed and pressures of neoliberal academia, where we are all encouraged to think in terms of impact factor and ranking, productivity and branding. Queer theory and research is arguably fairly institutionalized at this stage, at least in Nordic gender research. We have introductory books, historiographies and genealogies, and our research is increasingly taught and used, at least in some areas of academia. What kinds of new questions are being asked in such circumstances? What new areas of research are being developed in an era of expanding rights, recognitions, and visibilities?

It seems to us that even if there is nothing radically "new" in queer studies, the present points to a number of topics that are worthy of new - and renewed - attention. Looking back from this side of the new year, it is clear that 2018 was a year when issues related to gender and sexuality once again took center stage in national, regional, and international politics in a range of ways. We saw the closing down of gender stud- 
ies programs in Hungary and growing attacks on scholars and research that has critical perspectives on gender and sexuality around Europe and the world. We witnessed the election of an extremely neoliberal and many would say, fascist-leaning president in Brazil, whose political platform centrally pivots around "stopping gender ideology" and explicit anti-LGBTQ agenda. We watched as the US president continued to be immune to criticism of both his sexual harassment and his tempertantrums around his beloved wall to Mexico, but who also attempted to put a stop to all progressive trans politics with arguments such as that sex should be defined as "immutable biological traits identifiable by or before birth" (Green et al. 2018). In Sweden we went through months of awaiting a new government, got a budget which reminded us that the majority of Swedes ( $58 \%$ ) voted for the alliance parties and the Sweden Democrats, and among its many devastating effects on culture, public space, and equality were the explicit aim to shut down the national agency for gender equality. We experienced a growing number of attacks on gender studies scholars and units, including a bomb threat to the national secretariat for gender research. If we needed any "proof" that the fantasy of progress is just that, a fantasy, well, now we have it. We are back in the streets defending sexual, gender, and reproductive rights in their most basic democratic form. In these seemingly apocalyptic times, the themes and questions explored in queer studies are in other words under threats from powerful, conservative, anti-democratic forces. This includes the foundational idea for the field, namely that gender and sexual orientation are not given, static or universal, but rather, like categorizations such as "normal" and "deviant," effects of historical, institutional, and discursive power relations. Currently powerful forces seek to reinstate binary complimentary gender as natural and necessary for the reproduction of society and culture.

The number of new networks, projects, and symposia have been built to address these questions in recent times suggests renewed interest and urgency. Throughout the past year and into the current, the number of both public lectures and scholarly outputs around questions of austerity, neoliberalism, growing fascism and anti-democratic movements has 
grown, along with workshops and conferences organized to address the attacks on gender studies, gender and sexual politics, and the growing anti-democratic trends. It is clear that we need conceptual innovation and new approaches to these topics. An innovative approach is that of one of our international editorial board members, professor Kath Browne at Maynooth University in Ireland, who has received a prestigious consolidator grant from the European Research Council for a project entitled Opposing Sexual and Gender Rights and Equalities: Transforming Everyday Spaces (Maynooth University 2018). The project extends Browne's long standing work on LGBTQ livelihoods and resistance to LGBTQ rights and in particular, what happens to those who feel that they lose something when LGBTQ people gain increasing rights to marriage, and family and gender recognition. This timely and urgent international project will continue to develop the concept "heteroactivism," and aims to develop new methods for dialogue between groups who typically understand one another as "enemies." Browne's project aims to develop new approaches and boldly, also to provide new solutions.

These major shifts are clearly global in nature and this means we must address questions of gender and sexuality through global frameworks. Last year, one of our sister journals, Sexualities celebrated its $20^{\text {th }}$ anniversary. Indeed, in his retrospective founding editor reflections, Ken Plummer (2018) comments on the degree to which apocalyptic thinking now shapes all of us and the fields we are in. If the AIDS epidemic tied homosexuality to death, recent decades have increasingly tied some of its wealthier and healthier elements to life and futurity. Indeed, beyond its depressing gender and sexual politics, 2018 was a year when both regionally and globally, it became hard to deny the sense of looming environmental and economic catastrophe, even if world leaders continue to deny it. In addition to new fear waves around (nuclear) war, continued migration and extinction of all kinds of life forms, and of an end to the anthropocene as we have come to know it, this particular temporality radically alters understandings of both futurities and pasts.

Plummer (2018, I208) notes that in the past decades, critical studies of sexualities have truly begun to take on "global sexual, intimate and 
political complexities." Coupled with this is another new phenomenon; namely the growing digitalization and mediation of all forms of social life, including intimacy, reproduction, and democracy, which have radically changed both how we understand and how we research these very phenomena. As they get increasingly entangled in the continuous commodification and marketization of sexuality, we now witness both growing inequalities and a heightened emphasis on the fantasy of choice that obscures the significance and specificity of growing rates of precarity and marginalization, Plummer argues. Growing numbers of refugees, along with increasing rates of terrorism and violence, including by the liberal state against many of its subjects along with growing waves of populism and right-wing fundamentalism also challenge the imagined democratization and rise of LGBTQ rights. It is clear that questions of gender and sexuality remain at the heart of nation state politics, and as futurity is an increasingly uncertain idea, we urgently need more research on these topics. It remains to be seen if funding is diminishing on these topics or if what we need are projects that strongly bring to the fore their urgency for a range of crucial political topics, including environmental studies, migration, reproduction, and democracy.

It seems to us editors that in the world writ large and certainly in the Nordic region, questions of migration, asylum and "integration" as white-dominated heterosexual society tends to describe that process of "assimilation" into normative societal structures remains a crucial and urgent topic, one that in this issue is taken up by Deniz Akin to discuss the discourse around "authentic" LGBTQ refugees in the context of Norway. It remains to be seen what will happen with homonationalist politics in times of extreme right-wing conservatism; will commitments to the white nation render non-heterosexual citizens acceptable? What we clearly need, in times of growing racism and renewed efforts to rebuild the nation and with it the heterosexual family, is equal attention to how race, in both past and present conceptualizations, continue to shape our bodily and reproductive abilities, our citizenship, our chances at getting education, housing and work, or sexed and gendered "identities." And it goes without saying, at least to some of us, that we certainly 
need to renew our attention to and theorization of whiteness as "norm" in LGBTQ politics and research, as well as in society, in the same way we continue to analyze how heterosexuality as a norm shapes both gendered and sexual livelihoods and futurities and the theorization thereof.

Given the rise of attacks on both activism and scholarship dedicated to sexual, gender, and reproductive rights, we must continue paying attention to the effects of a near-global form of neoliberal economics. In particular, it seems to us that here in the Nordic region, we need to attend to how the very neoliberal project that helped facilitate gay rights, pink money, increasingly commodified and commercial Pride events and a rise of popular culture based in identity politics, has also given rise to homonationalism (Sörberg 20I7) and even worse, authoritarianminded leaders who win elections on agendas that are explicitly against sexual and gender rights. It is undeniable that neoliberalism is an economic system that has made the stratification of anything we might call an "LGBTQ community" more visible and acute. While some LGBTQ subjects now enjoy recognition and reproductive futurities at high costs via the transnational fertility market, others die in the streets by their own hands or just as frequently at the hands of fascists, racists, and homophobes, not to mention by the police state.

It may be the urgency of current concerns on a level of planetary extinction, the growing force of systemic racism and many other factors, that have led to many queer scholars turning to different projects and other kinds of questions than those reducible to LGBTQ. A new trend we have picked up on in the last years is the turn to projects on reparation and the human, to biopolitics and reproduction, and to queer ecologies. Perhaps it is time to once again go off the beaten track, even to do as Jack Halberstam, together with fellow bully blogger Tavia Nyong'o (2018) have recently done - turn to theories of the wild. Their introduction to a recent special issue on the topic, immediately points to links to queer insofar as wildness "names, while rendering partially opaque, what hegemonic systems would interdict or push to the margins" (Halberstam and Nyong'o 20I 8, 453). Drawing on, among others, the utopian thinking of the late José Esteban Muñoz, they argue: 
Wild theory subscribes to an understanding of the political that is not coextensive with our fucked-up political present, but nor does it appeal to an idealized anarchism of the past. (Halberstam and Nyong'o 201 8, 459)

Animating the desire to revisit the wild is the strong intersectional trajectories of recent queer theorizing and the refusal to limit queer politics and imaginaries to the national framework. In the aforementioned recent retrospective of Sexualities, a number of brief entries on themes in the field are also offered, and US queer anthropologist Martin Manalansan (2018) writes of "queer of color critique," a term often attributed to Roderick Ferguson (2004) whose crucial critiques of race, gender, and sexuality as shaped by cultural, economic, and epistemological formations introduced a new mode of discourse. Among the many important points made in this brief text and on a topic that we are yet to see extensively developed within the Nordic region, Manalansan (2018) points to how queer of color critique has centrally shown the entangled nature of queerness and the normative in everyday spaces and lived realities. The too often rehearsed dichotomy between queer and straight, deviance and norm hides rather than illuminates the messiness of everyday life, Manalansan contends. Queer of color critique, he writes, offers not so much a way out as a survival guide for managing the neoliberal mess we are in (Manalansan 2018, I288). In a way, this strand of research engages with the growing tradition of scholarship of hope, where hope itself is not located in religious ideas of divine intervention, but more becomes a mode of staying with the trouble of the world we have inherited.

\section{This Issue}

It is clear that queer remains a fluid and dynamic concept that does a lot of different work. We are pleased to finally offer you this double issue, which presents a range of promising new scholarship by emerging scholars. First out is Deniz Akin, one of few queer scholars in the Nordic region writing on LGBTQ questions of migration, race, and asylum, discusses how a genuine LGBT refugee subject is constructed in Norway through legal, political, and cultural discourses. Using queer theory 
and empirical data from her $\mathrm{PhD}$ thesis, Akin argues that the genuine LGBT refugee subject is discursively constructed as someone who is willing to be publicly visible, vulnerable and not threatening to the host society. The truth about what a genuine LGBT refugee subject looks like is established beforehand, and the asylum seekers are forced to display recognizable accounts of genuine refugee status in order to get asylum. This article raises a range of questions about who the subject of LGBTQ politics and research is and how the normative frames of secular, national whiteness shape marginalized livelihoods in globalized times.

Lena Sotevik, another emerging scholar, studies queerness in relation to ideas of children and childhood. Her article is based on two case studies: a focus group interview with pre-school teachers working at a LGBTQ certified pre-school and social media responses to the introduction of lesbian characters in the children's comic Bamse. Sotevik shows how queerness is viewed as desirable in both these contexts, but at the same time, heterosexuality passes by unnoticed while queerness is seen as something remarkable. For us this raises questions around the (im)possibility of assimilation, the contradictions of the simultaneous elevation of the queerly different and the fatigue that comes from coming up against invisible norms.

Through interviews, Sara Litzén has researched interest and investments in girliness, feminism, and fashion. Her article centers on "willful girliness," a concept she launches by drawing on Sara Ahmed and an extensive (Nordic) tradition of girlhood studies to analyze a particular kind of girliness that is linked to consciousness and feminism, and that her interviewees invest in. Litzén insightfully argues that willful girliness has to be understood as a historical construction, a kind of "doing," rather than a personal quality located in an individual, and that the concept has to stay open to be able to include new forms of girliness. This article not only contributes to further understandings of femininity in neoliberal and digitalized times, it illuminates the strength of a discourse that understands individual femininity as a resource. Whether this willfulness is wild or complicit with neoliberal logics remains to be investigated. 
In a quantitative, questionnaire-based study, Alexis Rancken explores the linguistic practices at work when partners and family members are referenced by Swedish-speaking people in Finland who define their relationships and/or family structures as against the norm. As Rancken acknowledges, the Swedish language is gendered in the area of romantic and family relationships, and this vocabulary can, and often does, contribute to reproduce norms regarding gender and sexuality. Many of the respondents in Rancken's study use gender-neutral language and personal expressions when speaking of their close ones, both partners and children, and Rancken argues that this can be seen both as a strategy to resist normative language systems and as a way of avoiding homophobic reactions. As a study of the gendered dimensions of queer intimacy and its entanglements with discursive norms, Rancken's emerging scholarship exemplifies both the existence, and the importance, of continued qualitative research on those communities that are now under attack from anti-gender movements.

Returning to how legal frameworks continue to shape and determine whose lives and bodies are worth defending that Akin's article also addressed, Malte Breiding Hansen analyzes the opposition between universalist and cultural relativist standpoints in United Nation disputes about human rights for sexual and gender minorities. Using Michel Foucault's concept of truth regimes, he shows how the polarization between the two standpoints obstructs national implementation of human rights in the case of sexual and gender minorities. Breiding Hansen concludes by arguing for a top-down and a bottom-up approach to avoid the polarization and actually allow for human rights recognition for culturally diverse sexual and gender minorities.

In the essay section, we first turn to new forms of queer art. Art arguably produces new kinds of queer knowledge insofar as it frames queer lives and experiences in a different way than academic research and theory. Here Sara Lindquist's photographic essay raises questions about queer lives in northern Sweden. It contains portraits from Lindquist's series of images Hen och jag [They and me], as well as a short text where Lindquist writes about this project, situating it in the context 
of northern Sweden. This essay also gestures to our upcoming special issue on queer in rural areas, guest-edited by Anna Olovsdotter Lööv and Evelina Liljeqist.

The journal's We're Here section as always aims to illuminate a current theme or trend. This time Tiina Rosenberg interrogates the new wave of right-wing populism and nationalism in Europe and the Nordic region. Rosenberg's essay in Swedish takes stock of the situation and argues that LGBTQ people cannot take the rights we have gained over the last decades for granted and that we need to stand up for democratic rights for all through a politics firmly grounded in intersectionality. Right-wing nationalism is a threat not only to half the population which is now encouraged to once again see its main contribution to life and society as that of wife and mother, but above all to all minorities. Rosenberg points to the importance of joining forces and fighting back together.

We also offer a number of reviews of new literature in our field. It is the last issue that our colleague and excellent review editor Ann-Sofie Lönngren will do, as she is now moving on to other tasks. We take this opportunity to thank Ann-Sofie for her exemplary work and contributions to the overall editorial process. At the same time, we are also saying farewell to Karin Lindeqvist, who has been the indispensable editorial secretary of lambda nordica throughout our term as senior editors. To even begin to imagine producing this journal without Karin's sharp editorial eye, breadth of knowledge of the field, and gentle stylistic guidance of our authors, is difficult. As we frequently point out, to produce an issue of a journal takes a village, and Karin has been the spider in the web. 2019 is bound to bring many more changes both for this journal and for the world. We remain curious and interested in hearing from our readers and authors, and are dedicated to making a journal that reflects the breadth of research emerging in our field. Stay tuned and please continue to read, cite and contribute to making lambda nordica a place of wild theorizing, hopeful scholarship, and a guide with which to continue to navigate the mess we are in. If, as Halberstam and Nyong'o contend, turning to wildness is less a reclaiming like that of queer and more of an attunement to what the wild teaches us about survival in 
apocalyptic times, then attending to what it "has always gathered in its wake and what it gestures toward in terms of the expunged features of our own critical systems of making sense and order" (Halberstam and Nyong'o 20I 8, 454), seems a good place to start.

\section{JENNY BJÖRKLUND and ULRIKA DAHL, CO-EDITORS}

\section{REFERENCES}

Ferguson, Roderick A. 2004. Aberrations in Black: Toward a Queer of Color Critique.

Minneapolis: University of Minnesota Press.

Green, Erica L., Katie Benner, and Robert Pear. 2018. “'Transgender' Could Be Defined Out of Existence under Trump Administration." The New York Times, October 21. https://www.nytimes.com/2018/ro/2I/us/politics/transgender-trumpadministration-sex-definition.html.

Halberstam, Jack, and Tavia Nyong'o. 2018. "Introduction: Theory in the Wild." South Atlantic Quarterly I17.3:453-64. https://doi.org/10.1215/00382876-694208I.

Manalansan, Martin F. 20r8. "Messing Up Sex: The Promises and Possibilities of Queer of Color Critique.” Sexualities 21.8:1287-90. https://doi. org/Io.I177/136346071 8794646.

Maynooth University. 2018. "Maynooth University Prof Kath Browne Awarded Prestigious ERC Grant.” December 4. https://www.maynoothuniversity.ie/news-events/ maynooth-university-prof-kath-browne-awarded-prestigious-erc-grant.

Plummer, Ken. 2018. “Sexualities: Twenty Years On.” Sexualities 21.8:1204-10. https://doi.org/Io.1177/1363460718788348.

Sörberg, Anna-Maria. 2017. Homonationalism. Stockholm: Leopard. 